\title{
VAPOUR DETECTORS FOR GAS CHROMATOGRAPHY
}

\begin{abstract}
A $\mathbf{N}$ informal symposium on "Vapour Detectors for Gas Chromatography" was held in the Physical Chemistry Laboratory, Oxford, on May 3. The meeting was organized by the newly formed Gas Chromatography Discussion Group associated with the Institute of Petroleum, and was the first of a series of such meetings to be held twice yearly at centres throughout the country. More than two hundred participants attended and six papers were presented, the chairman and local organizer being Mr. C. S. G. Phillips.

In an introductory paper, Dr. A. I. M. Keulemans emphasized the importance of the detector in gas chromatography and the necessity for a continual improvement in its sensitivity. He directed attention to the recommendations made at the symposium in London during May $1956^{1}$, concerning the description of detector characteristics, and suggested that the method described by Dimbat, Porter and Stross ${ }^{2}$ for comparing sensitivities was generally applicable. This expresses the sensitivity, $S$ (in units of $\mathrm{mV} . \mathrm{ml}$.) mgm.), in terms of the peak area obtained for a given weight of a component, but is only suitable for use with a chromatographic assembly of column and detector. A statement of the noise level, $s$ (in microvolts), is also required. The sensitivity of the detector alone is better defined as the minimum detectable vapour concentration ( $\gamma / \mathrm{ml}$. carrier gas), for a specific signal to noise ratio. Another speaker later commented that high sensitivity without a reasonably small detector volume and short time of response is not particularly useful for chromatographic purposes. Dr. Keulemans continued with a brief consideration of the relative merits of the thermal conductivity and $\beta$-ray ionization detectors. Although sensitive katharometers are comparatively easy and cheap to construct $(S=300-1,000, s=0-20$ ) they suffer from two defects, namely, non-linearity of response, which necessitates calibration; and decomposition of vapours at high temperatures. These defects are largely overcome with the ionization detector, which can achieve a similar sensitivity and is much less sensitive to temperature changes. Expensive amplifying equipment is required, however.
\end{abstract}

The next two papers dealt with ionization detectors employing radioactive sources. Dr. H. Boer discussed the stability of the single-cell $\beta$-ray detector developed in the United States ${ }^{3}$ compared with that of the balanced twin-cell arrangement he had already described (ref. 1, p. 169). To achieve a satisfactory zero drift, it is necessary to control the temperature of the former to within one-tenth per cent of the absolute temperature, but the latter is very much less sensitive. He had found it completely satisfactory to heat the twin-cell with infra-red lamps in a simple oven without a thermostat. Optimum cell depths, of the order of $15 \mathrm{~mm}$., are only a fraction of the free path length of the $\beta$-particles in air, and tend to decrease with increasing source strength and become larger as the polarizing voltage is increased. The detector gives a good quantitative response with low vapour concentrations; corrections due to ionization cross-section are usually not very important. Dr. Boer finally described a modified twin cell detector requiring only a simple double triode amplifier, which was being tried at temperatures greater than $250^{\circ} \mathrm{C}$.

In the second paper, Dr. J. E. Lovelock described another balanced twin-cell arrangement, but with the radioactive sources in the form of foil and with guard-rings on the ion collectors. He claimed, however, that the use of argon as carrier gas allowed a gain in sensitivity over the cross-section detector of at least on $\Theta$ hundred to be achieved. This is possible because of the unique ionization properties of this gas. In common with the other rare gases, argon produces, on irradiation, many more excited atoms than ions, but the energy of these excited argon atoms is comparatively low (about $11.5 \mathrm{eV}$.). Additional ionization of vapour molecules by collision with these atoms occurs, but their energy is insufficient to affect any of the contaminants found in commercial argon. Although a 10-millicurie strontium-90 source was normally employed, the higher sensitivity made possible the use of an 80 -microcurie radium source. With a polarizing voltage of about $700 \mathrm{~V}$. the response had been shown to be linear at low vapour concentrations and a close function of the mole fraction for most common organic structures. The current produced by the detector is of the order of $5 \times 10^{-9}$ amp., and this is recorded with the assistance of a simple electrometer amplifier. Dr. Lovelock commented that the detector had been successfully operated from $20^{\circ}$ to $200^{\circ} \mathrm{C}$., and that no zero drift took place when raising the column temperature through this range during the course of an analysis. Normal column loadings were in the range $0 \cdot 1$ $1 \mathrm{mgm}$. when the minimum detectable amount at a signal to noise ratio of $2: 1$ was $5 \times 10^{-7}$ moles.

The afternoon session opened with a paper by $\mathrm{Mr}$. J. C. Hawkes on the use of the gas density balance at high temperatures. An earlier apparatus described by the author (ref. 1, p. 266) had operated successfully up to $300^{\circ} \mathrm{C}$. using a vapour jacket. In considering a design to operate from $200^{\circ} \mathrm{C}$. to as high as $550^{\circ} \mathrm{C}$., difficulties with gaskets and the lack of thermally stable boiler liquids had necessitated the adoption of electrical heating for both the block and columns. The construction of the latest model was nearly complete and the uniformity of the temperature along the column had been kept within $2^{\circ} \mathrm{C}$. even at an operating temperature of $500^{\circ} \mathrm{C}$. Platinum resistance thermometers are employed as temperature controllers operating in an a.c. bridge circuit through phase-sensitive amplifiers to control the electrical input. In this way thermostatting to \pm 0.3 per cent of the operating temperature is achieved. Many difficulties had been encountered in devising modes of construction to withstand the large temperature changes, particularly with the anemometer heater and thermocouple supports. The most satisfactory heater arrangement achieved had a hollow invar shaft surrounding a twin-hole porcelain tube through which stainless steel lead-wires passed. These were sealed to the ceramic with soda glass. To prevent corrosion the inside of the balance had been coated with nickel by a non-electrolytic method ${ }^{4}$. An interesting sample introduction system employing a 
glass-phial crusher was described for use with the equipment.

The next speaker, Mr. J. R. Bishop, discussed the use of directly heated bead thermistors in thermal conductivity detectors. He presented data on the sensitivity of five different types of elements of both British and American manufacture. Using nitrogen as carrier gas, $S$ values of 100-600 had been obtained with noise level lower than 10 microvolts. All types examined are stable up to $150-160^{\circ} \mathrm{C}$. in nitrogen but with hydrogen as carrier gas the upper limit is only $100^{\circ} \mathrm{C}$. at low bridge currents. With a bridge current of 15 milliamp. in hydrogen, noise appears, especially with uncoated beads, and at higher currents irreversible changes take place. A simple arrangement with a single thermistor supported in an extension $8 \mathrm{~mm}$. in diameter at the end of a glass chromatographic column is effective and has a low detector volume. It is inherently sensitive to flow and this is best compensated by using another thermistor in the bridge, placed at the end of a second column. With the two elements connected in parallel to the applied voltage it was shown that the sensitivity was highest when the two fixed bridge resistors had values lower than the operating resistance of the thermistors. A detector with four thermistors connected in a bridge, which should give even higher sensitivity, was being constructed. Mr. Bishop directed attention to new American thermistors capable of operation up to $300^{\circ}$ C., and illustrated the robustness of modern elements by describing how a colleague regularly cleans his detector with strong sulphuric acid. In conclusion, he commented on the possible use of thermistors for vapour detection based on specific heat rather than thermal conductivity differences.

One of the most recent detectors described, the low-pressure electric discharge, formed the subject of the last paper, by Dr. R. C. Pitkethly. Preliminary experiments with simple discharge tubes similar in construction to that used by Harley and Pretorius ${ }^{5}$ demonstrated the very high sensitivity of the voltage drop across the discharge to small changes in concentration of hydrocarbon vapours in a stream of nitrogen passing through it. Early tubes, with platinum electrodes spaced a few centimetres apart, were very noisy and showed a poor linearity of response, with tailing of the peaks. These effects were attributed to electrode sputtering, changes in the number of bands in the positive column, poor scavenging and pronounced pressure sensitivity. An improved detector tube, employing a modified small neon indicator bulb, had been developed. This had comparatively large closely spaced iron electrodes, and was run at a pressure of about $3 \mathrm{~mm}$. mercury with 200 $300 \mathrm{~V}$. across it. A pair of these tubes were connected to the ends of two columns with fine capillary tube, which provided the necessary pressure drop. They were operated in a simple bridge circuit with a double triode impedance changer to enable a standard highspeed potentiometric recorder to be employed. With this arrangement operated at room temperature, it is easily possible to detect a concentration of paraffin hydrocarbon gases in nitrogen of one part in ten million by volume. In the range $\mathrm{C}_{3}-\mathrm{C}_{8}$, the response to paraffins eluted in nitrogen from a column ranged from 9 to 38 volt-litres per micromole, rising with molecular weight. This sensitivity in the units proposed earlier is of the order of $3 \times 10^{8} \mathrm{mV}$. ml./mgm. with a noise level of $20 \mathrm{mr}$.

Before closing the meeting, the chairman invited Mr. R. P. W. Scott to describe his recent work with the hydrogen flame detector. A miniature bunsen burner-like attachment had been fixed to the top of the jet, which produced a pre-mixed flame more compact and stable than the original diffusion type. This, in conjunction with a platinum-rhodium/ platinum thermocouple $0.004 \mathrm{in}$. in diameter on an improved support, had produced a marked increase in sensitivity. The minimum detectable concentration was now about $0.07 \mathrm{\gamma} / \mathrm{ml}$. with a signal to noise ratio of four.

D. H. Desty

"Vapour Phase Chromatography". Proceedings of a Symposium held in London, May 1956 (Butterworths, 1957).

${ }^{3}$ Dimbat, M., Porter, P. E., and Stross, F. H., Anal. Chem., 28, 290 (1956).

Deal, C. H., Otvos, J. W., Smith, V. N., and Zucco, P. S., Anal. Chem., 28, 1958 (1956).

- Breuner, A., Couch, D. E., and Williams, F. K., J. Res. Nat. Bur. Stand., 44, 109 (1950).

'Harley, N., and Pretorius, V., Nature, 178, 1244 (1956).

\section{TRACE ELEMENTS IN SOILS, PLANTS AND ANIMALS}

$M$

ORE than one hundred people listened with interest to papers and discussion at a symposium on trace elements in soils, plants and animals which was held in Bristol during April 10-12. Seven papers out of seventeen were contributed by workers at Long Ashton. C. Bould spoke on iron chelates for control of chlorosis in plants. With fruit trees, good results were obtained by applying chelates to the soil, provided that they were well watered in so that they reached the rooting zone before their iron was liberated by interaction with calcium. For strawberries or blackeurrants seasonal cure of chlorosis could be obtained by foliar sprays : a good wetting agent was essential. If chelates are absorbed in excess by plants there is a risk that minor elements may be affected. E. J. Hewitt reported that, with cauliflower, molybdenum is required not only for reduction of nitrate; when toxic accumulation of nitrate is avoided, by supplying nitrogen in other forms, deficiency of molybdenum has disturbing effects involving limited growth, reproductive failure and low concentration of ascorbic acid and, in cauliflower, symptoms of whiptail. In discussion it was mentioned that soil acidity, which is normally accompanied by lack of calcium, may cause plant injuries due to deficiency of molybdenum or excess of manganese and aluminium. D. J. D. Nicholas reported that in Neurospora and in green plants the step-wise reduction of nitrate to nitrite, to hyponitrite, to hydroxylamine, to ammonia was effected by flavin enzymes dependent on molybdenum, on copper and iron, on copper and iron, and on manganese, respectively. An alternative to the final step is the non-enzymic reaction of hydroxylamine with ketonic acids, resulting in the formation of oximes which are then reduced enzymically to aminoacids. That molybdenum is a constituent of nitrate reductase has been shown, because activity of the enzyme was diminished after dialysis in the presence of cyanide but was largely restored by adding molybdenum to the apoenzyme, whereas addition of various other elements was without effect. Strains of Azotobacter and Clostridium require molybdenum and iron for nitrogen fixation; in some instances vanadium or tungsten can replace molybdenum in this process. The hydrogenase enzyme, which is primarily irondependent, is not invariably coupled with nitrogen 